\title{
In-vitro assessment of antioxidant and antimicrobial activities of methanol extracts and essential oil of Thymus hirtus sp. algeriensis
}

\author{
Guesmi Fatma1*, Ben Farhat Mouna', Mejri Mondher ${ }^{2}$ and Landoulsi Ahmed
}

\begin{abstract}
Background: Owing to the complexity of the antioxidant materials and their mechanism of actions, it is obvious that no single testing method is capable of providing a comprehensive picture of the antioxidant profile. The essential oil of the Thymus specie may still possess other important activities in traditional medicine, it can be used in the treatment of fever and cough. This essential oil may also have an anticancer activity.

Methods: The essential oils aerial parts hydrodistilled from Thymus hirtus sp. algeriensis, were characterised by GC/MS analysis and the methanolic extracts were chemically characterized by HPLC method. The essence of thyme was evaluated for its antioxidant and antibacterial activity.

Result: The Terpinen-4-ol are the principal class of metabolites (33.34\%) among which 1.8-cineole (19.96\%) and camphor (19.20\%) predominate. In this study, quantitative values of antioxidant activity of crude methanolic extracts of Thymus hirtus sp. algeriensis were investigated. The essential oils was screened for their antibacterial activity against six common pathogenic microorganisms (Escherichia coli, Pseudomonas aeruginosa, Salmonella enteridis, Staphylococcus aureus, Bacillus subtilis and Listeria monocytogenes) by well diffusion method and agar dilution method (MIC). All the essences were found to inhibit the growth of both gram (+) and gram (-) bacteria organisms tested. These activities were correlated with the presence of phenolic compounds in active fractions. HPLC confirmed presence of phenolic compounds in methanol extracts.

Conclusion: Methanol extracts and essential oils from aerial parts of Thymus hirtus sp. algeriensis, were examined for their potential as antioxidants. The technique for measuring antioxidant activity, which was developed using DPPH, ABTS and $\beta$-carotene bleaching, produced results as found in established literatures. The present results indicate clearly that methanol extracts and essential oils from Thymus hirtus sp. algeriensis possess antioxidant properties and could serve as free radical inhibitors or scavengers, acting possibly as primary antioxidants, also their essential oil have an antibacterial effect.
\end{abstract}

Keywords: Radical scavenging effect, Phenolic compounds, Essential oil, Antioxidant activity, Antibacterial activity

\section{Background}

Thymus hirtus sp. algeriensis (thyme), locally known as "Mougecha" or "Mazoukcha", a member of the Lamiaceae family, is the most widespread North African species. In Tunisia, Thymus hirtus sp. algeriensis populations are distributed from the sub-humid to the lower arid bioclimates and grow at altitudes ranging from 120 to 1100

\footnotetext{
* Correspondence: fguesmi77@yahoo.com

'Laboratory of Biochemical and Molecular Biology, Faculty of Science of Bizerte, University of Carthage, Bizerte, Tunisia

Full list of author information is available at the end of the article
}

[1]. The species grow on poor fertile calcareous soils and occurs in scattered and small populations. Thymus hirtus $s p$. algeriensis is a short lived shrub, described as diploid $(2 \mathrm{n}=2 \times=30)$ and gynodioecious species [2]. It is often pollinated by bees (allogamous species); however self-pollination may occur in hermaphrodites [3]. The genus Thymus has numerous species and varieties and their essential oil composition have been studied earlier [4]; consists of about 350 species of perennial, aromatic herb and sub shrubs native to Europe and North Africa. Various species of thyme is used all over 
the globe as condiments, ornamentals and sources of essential oil [5]. Thymus hirtus sp. algeriensis is largely used, fresh or dried, only as a culinary herb and widely used in Tunisian folk medicine as anti-inflammatory, anti-diarrheic and anti-bronchic agents. Furthermore, this plant is widely used in folk medicine against illnesses of the digestive tube and antiabortion [6]. Essential oil of this specie was found to possess an interesting inhibitory activity towards angiotensin I-converting enzyme suggesting the potential of this plant as an antihypertensive agent [7].

Thyme oil is among the world's top ten essential oil, displaying antimicrobial [8], antimycotic, antioxidative [7], food preservative, antifungal [9] and mammalian agedelaying properties [10]. A relatively high level of differentiation $\left(\mathrm{F}_{\mathrm{ST}}=0.146\right)$ between some population of Thymus hirtus sp. algeriensis associated with a restricted gene flow among populations $\left(\mathrm{N}_{\mathrm{m}}=2.385\right)$ was revealed according to the geographical regions [3] and to the vegetative stage [11]. Due to application of Thymus hirtus sp. algeriensis growing wild in Tunisia in folk medicine, the purpose of the present work was to evaluate the antioxidant and the antibacterial potential of their essential oils and methanolic extracts against an epidemiological relevant group of bacterial food-borne pathogens and relate it with their chemical composition, for further application in food and pharmaceutical industries as natural valuable products. All extracts were chemically characterized by HPLC method in order to find the connection between their activity and chemical composition of extracts.

\section{Material and methods}

Plant material

The flowering aerial parts of the studied Thymus species were collected randomly from three different locations in Tunisia, in March 2010. Gafsa (MG) (in the high lands); Tamerza (MT) (in the high lands) and Kairouan (MOK) (near to dam) (Table 1). The taxonomic identification of plant species were confirmed by the forest engineer of Bouhedma Natural Park, and a voucher specimen was deposited at the herbarium of the Laboratory of Medicinal Plants (INAT). The dried aerial parts were powdered and then used for extraction.

\section{Preparation of the extracts}

Briefly, $9 \mathrm{~g}$ of powdered aerial parts were continuously extracted in absolute methanol for $8 \mathrm{~h}$ using a Soxhlet apparatus. The extracts were concentrated to dryness using a rotary evaporator. The extract yields $(\mathrm{w} / \mathrm{w})$ were $24.2 \%$ for MT, $15 \%$ for MOK and $18 \%$ for MG.

\section{Isolation of the essential oil}

A portion (100 g) of dried and ground aerial parts of Thymus hirtus sp. algeriensis were submitted to waterdistillation for $3 \mathrm{~h}$ using a Clevenger-type apparatus. Sample was dried over anhydrous $\mathrm{Na}_{2} \mathrm{SO}_{4}$ and kept in a refrigerator $\left(4^{\circ} \mathrm{C}\right)$ for subsequent experiments. The thyme essential oils (yields of MT, MG and MOK are respectively $10.82 \%(\mathrm{v} / \mathrm{w}), 2.36 \%(\mathrm{v} / \mathrm{w})$ and $5.75 \%(\mathrm{v} / \mathrm{w}))$; was analyzed using a fused silica capillary column, HP5-MS.

\section{GC/MS analysis conditions}

Samples of $1 \mu \mathrm{l}$ (dilution in hexane 10\%) were subjected to analysis by GC-MS. The GC analysis was performed on a model 7890 A (series II) gas chromatograph, with a flame ionisation detector (FID) and split ratio of 1:50 using a fused silica capillary column, HP5-MS (30 m × $250 \mu \mathrm{m}$ i. d., $0.25 \mu \mathrm{m}$ film thickness). The injector or detector temperature for each analysis was about $250^{\circ} \mathrm{C}$, plus the carrier gas was helium at a flow rate of $0.8 \mathrm{ml} / \mathrm{min}$. The peak areas were measured by electronic integration, and the relative amounts of the individual components based on the peak areas. The GC-MS was carried out on an Agilent model $5975 \mathrm{C}$ mass spectrometry operating in the ionizing energy mode at $70 \mathrm{eV}$, combined with the GC described above.

The temperature of the column was programmed from $60^{\circ} \mathrm{C}$ to $240^{\circ} \mathrm{C}$ at $4^{\circ} \mathrm{C} / \mathrm{min}$. The injector and ion source temperatures were the same as mentioned above. Scanning from m/z 50-550 at $2.91 \mathrm{scan} / \mathrm{s}$. The quadrupole temperature was $150^{\circ} \mathrm{C}$, and the electron multiplier voltage was maintained at $1188 \mathrm{~V}$. The constituents were identified by comparison of their retention indices with those of the literature (Adams, 1995). The retention indices were determined in relation to a homologous series of $n$-alkanes $\left(C_{10}-C_{15}\right)$ under the same operating conditions.

High performance liquid chromatographic identification and quantification of phenolic and flavonoid compounds in plant extracts

The HPLC was performed using KNAUER chromatographic system; equipped with a diode array UV detector

Table 1 Collection sites of cultivated Thymus hirtus sp.algeriensis and their eco-geographical characteristics

\begin{tabular}{|c|c|c|c|c|c|c|c|c|c|}
\hline \multirow[t]{2}{*}{ No. } & \multirow[t]{2}{*}{ Collection site } & \multirow[t]{2}{*}{ Code } & \multirow{2}{*}{$\begin{array}{l}\text { Bioclimatic } \\
\text { stage }\end{array}$} & \multirow[t]{2}{*}{ Soil pH } & \multirow{2}{*}{$\begin{array}{l}\text { Rainfall } \\
\text { (mm/year) }\end{array}$} & \multirow{2}{*}{$\begin{array}{l}\text { Temperature } \\
\left({ }^{\circ} \mathrm{C} / \text { year }\right)\end{array}$} & \multicolumn{3}{|c|}{ Geographical location } \\
\hline & & & & & & & Longitude (N) & Latitude (E) & Altitude (m) \\
\hline 1 & Gafsa & $M G$ & Semi-arid & 8.1 & $220-400$ & $11-51.8$ & $9^{\circ} 05^{\prime} 00^{\prime \prime}$ & $34^{\circ} 46^{\prime} 67^{\prime \prime}$ & 340 \\
\hline 2 & Tamerza & MT & Arid & 7.5 & 200 & $12-50$ & $7^{\circ} 95^{\prime} 00^{\prime \prime}$ & $36^{\circ} 38^{\prime} 85^{\prime \prime}$ & 441 \\
\hline 3 & Kairouan & MOK & Semi-arid & $1-14$ & $400-800$ & 19-35 & $36^{\circ} 33^{\prime} 84^{\prime \prime}$ & $10^{\circ} 51^{\prime} 52^{\prime \prime}$ & 57.6 \\
\hline
\end{tabular}


model 2500. Eurospher $100-5 \mathrm{C}_{18}$ column $(250 \times 4.6 \mathrm{~mm}$ with percolumn). The mobile phase was methanol; acetonitrile $(50: 50 \mathrm{v} / \mathrm{v})$ (solvent A) and a mixture of water; acetic acid $(97: 3 \mathrm{v} / \mathrm{v})$ (solvent $\mathrm{B}$ ) at a flow rate of $1 \mathrm{ml} /$ min. The solvent gradient changed according to the following conditions: from $5 \%$ to $30 \%$ A for $25 \mathrm{~min}$; from $30 \%$ A to $38 \%$ A for $10 \mathrm{~min}$; from $38 \%$ A to $45 \%$ A for $10 \mathrm{~min}$; from $45 \%$ A to $53 \%$ A for $5 \mathrm{~min}$; finally, isocratic for $60 \%$ A to $65 \%$ A for $5 \mathrm{~min}$. Eluates were detected at $280 \mathrm{~nm}$ [12].

Phenolic compounds quantification was achieved by measuring the absorbance at $280 \mathrm{~nm}$ recorded the chromatograms relative to external standards. Phenolic compounds content were expressed in microgram per gram of dry plant material weight.

Total phenolic was determined by a miniaturisation of method developed by Singleton [13]. Appropriately diluted (15 fold), thyme extracts $(50 \mu \mathrm{l})$ was mixed with $400 \mu \mathrm{l}$ of Folin-Ciocalteu reagent $(10 \%)$ and $50 \mu \mathrm{l}$ distilled water and allowed to stand at room temperature for $5 \mathrm{~min}$. After 3 to $8 \mathrm{~min}$, soduim bicarbonate solution $(7,5 \%, 500 \mu \mathrm{l})$ was added to the mixture. Afterwards, the blue mixture was incubated at room temperature for $1 \mathrm{~h}$. Absorption at $725 \mathrm{~nm}$ was measured using a spectrophotometer. The total phenolic content was expressed as gallic acid equivalents (GAE). The concentrations of phenolic compounds were calculated according to the following equation that was obtained from the standard gallic acid graph:

$$
y=0.0016 x\left(R^{2}=0.8675\right)
$$

The determination of flavonoids was performed by Dewanto [14]. To $250 \mu \mathrm{l}$ of diluted thyme extract, 5\% sodium nitrite solution $(75 \mu \mathrm{l})$ was added. Tubes were incubated at ambient temperature for $6 \mathrm{~min}$, and then $10 \%$ of aluminium chloride solution $(150 \mu \mathrm{l})$ was added to the mixture, followed by $500 \mu \mathrm{l}$ of $1 \mathrm{M}$ sodium hydroxide. Immediately, the volume of reaction mixture was made to $2,5 \mathrm{ml}$ with distilled water. The mixture was thoroughly vortexed and the absorbance of the pink colour developed was determined at $510 \mathrm{~nm}$. A calibration curve was prepared with rutin and the results were expressed as rutin equivalents (RE).

The concentrations of flavonoids were calculated according to the following equation that was obtained from the standard rutin graph.

\section{Antioxidant activity $D P P H$ radical-scavenging activity}

$\mathrm{DPPH}$ is a stable nitrogen radical that bears no similarity to the highly reactive and transient peroxyl radicals involved in lipid peroxidation. Antioxidant assay is based on measurement of the loss of DPPH color after reaction with test compounds [15], and the reaction is monitored by a spectrometer.

To methanolic solution $(50 \mu \mathrm{l})$ of antioxidants (or essential oils) we added methanolic solution of DPPH $\left(2 \mathrm{ml}\right.$ of $\left.6.10^{-5} \mathrm{M}\right)$. The antioxidant tests were based on the measurement of the loss of DPPH colour at $515 \mathrm{~nm}$. The methanol is used to make at zero the spectrophotometer. BHT was used for comparative purposes.

All determinations were performed in triplex.

Free radical scavenging capacity was calculated by the following equation:

$$
\% \text { Inhibition }=\left(A_{\text {blank }}-A_{\text {sample }} / A_{\text {blank }}\right) \times 100
$$

Where Ablank and Asample stand for absorption of the blank sample and absorption of tested extract solution respectively.

Extract concentration that provide $50 \%$ inhibition $\left(\mathrm{IC}_{50}\right)$ and expressed in $\mu \mathrm{g}$ extract/ml was calculated from the graph plotted inhibition percentages against tested samples extracts.

The higher the $\mathrm{IC}_{50}$, the lower is the antioxidant activity of the examined sample.

\section{2, 2 -Azinobis-3-ethylbenzothiazoline-6-sulfonate (ABTS) radical scavenging assay}

The total antioxidant activity of extracts was measured using the ABTS assay, as described by Miller [16] to test biological samples and then was widely applied to test food and natural water-soluble phenolics. The idea of this method is to monitor the decay of the radical cation $\mathrm{ABTS}^{+}$produced by the oxidation of 2,2 -azinobis (3-ethylbenzothiaziline-6-sulfonate) (ABTS) caused by the addition of a phenolic-containing sample. ABTS ${ }^{+}$ has a strong absorption in the range of $600-750 \mathrm{~nm}$ that can be easily determined spectrophotometrically. In the absence of phenolics, ABTS ${ }^{+}$is rather stable, but it reacts energetically with a $\mathrm{H}$-atom donor, such as phenolics, being converted into a non-colored form of ABTS. The authors determined the quantity of ABTS ${ }^{+}$consumed due to reaction with phenolic-containing sample.

ABTS ${ }^{+}$reacts with any hydroxylated aromatics independently of their real antioxidative potential. The ABTS value was based on the ability of the antioxidant to scavenge the blue-green 2,2'-azinobis 3-ethylbenzothiazoline6-sulfonate $\left(\mathrm{ABTS}^{+}\right)$radical cation relative to the $\mathrm{ABTS}^{+}$ scavenging ability of BHT. ABTS ${ }^{+}$L'ABTS $^{\cdot+}$ is generated after chemical oxydation reaction with potassium persulfate $\left(\mathrm{K}_{2} \mathrm{~S}_{2} \mathrm{O}_{8}\right)(2.45 \mathrm{mM})$.

The concentration of radical solution ABTS blue-green is adjusted with methanol to an absorbance of $0.700 \pm$ 0.020 (mean \pm SD) at $734 \mathrm{~nm}$. To $280 \mu \mathrm{l}$ of this solution of ABTS $^{\cdot+}$ we added $20 \mu \mathrm{l}$ of extracts (or essential oils) or BHT or solvent. BHT was used for comparative purposes. 
The mixture is incubated during $5 \mathrm{~min}$ à $30^{\circ} \mathrm{C}$, and absorbance is measured at $734 \mathrm{~nm}$. All determinations were performed in triplicate.

\section{$\beta$-carotene/linoleic acid assay}

$\beta$-carotene is another important fat soluble antioxidant that quenches sites localised within the hydrophobic region of biological membranes, contrasting with the scavenging activity of $\alpha$-tocopherol close to the membrane surface [17].

The antioxidant capacity was estimated by thermally induced $\beta$-carotene bleaching assay, as described by Pratt [18] with some modifications. The assay reagent was prepared by mixing $0.5 \mathrm{mg}$ of $\beta$-carotene with $1 \mathrm{ml}$ of chloroform, $25 \mu \mathrm{l}$ of linoleic acid and $200 \mathrm{mg}$ of Tween 40 (polyoxyethylenesorbitanmonopalmitate). Chloroform was removed at $50^{\circ} \mathrm{C}$, under vacuum, using a rotary evaporator (Heidolph, Germany). The resulting mixture was immediately diluted with $100 \mathrm{ml}$ of oxygenated distilled water. Aliquots $(2500 \mu \mathrm{l})$ of this emulsion were transferred into different test tubes containing $350 \mu \mathrm{l}$ of test samples. The tubes were shaken and incubated at $50^{\circ} \mathrm{C}$ in a water bath.

BHT was used for comparative purposes. Absorbance of all samples at $490 \mathrm{~nm}$ were taken at zero time $(\mathrm{t}=0)$, measurement of absorbance was continued, until the colour of the $\beta$-carotene disappeared in the control reaction $(\mathrm{t}=1 \mathrm{~h})$, at $5 \mathrm{~min}$ intervals. A mixture prepared as above, without $\beta$-carotene, served as blank. All determinations were performed in triplicate.

$\beta$-carotene bleaching inhibition was measured by the following formula: ( $\beta$-carotene absorbance after $1 \mathrm{~h} /$ initial absorbance) $\times 100$ [19].

\section{Determination of antibacterial activity Disc diffusion assay}

The disc-diffusion assay [20] was used to determine the growth inhibition of bacteria by the plant essential oil. The bacteria used in this study including s.a ATCC 25923, B.s 166, E. coli GM 109, P.ae, S.e ATCC 502 and L. monocytogynes were obtained from the laboratory of microbiology, Pasteur Institute, Tunisia. Base plates were prepared by pouring Muller-Hinton $(\mathrm{MH})$ agar into sterile Petri dishes and allowed to set. Plant essential oil aliquots of $10 \mu \mathrm{l}$ were applied per filter paper disc (Whatman No $6 \mathrm{~mm}$ diameter). The disc were air-dried and placed onto the seeded top layer of the agar plates.

Each essential oil was tested (1 disc/plate), with a Penicillin $(30 \mu \mathrm{g} / \mu \mathrm{l})$, Chloramphenicol $(30 \mu \mathrm{g} / \mu \mathrm{l})$, and Streptomycin $(10 \mu \mathrm{g} / \mu \mathrm{l})$ discs as references or positive controls. Methanol saturated discs were used as negative controls. The plates were evaluated after incubation at $37^{\circ} \mathrm{C}$ for $18 \mathrm{~h}$.

Antibacterial activity was expressed as the ratio of the inhibition zone $(\mathrm{mm})$ produced by the plant essential oil and methanolic extract and inhibition zone caused by the reference [21]. The experiments were run in triplicate and averaged.

\section{Minimum inhibitory concentration (MIC) of plant extracts and essential oils}

Thymus hirtus sp. algeriensis essential oils with antibacterial activity were serially diluted to a working concentration ranging from $50-0.5 \mathrm{mg} \mathrm{mL}^{-1}$ for determination of their lowest inhibitory concentration (MIC) according to a previously described procedure [22].

\section{Results and discussion}

The amount of total phenolics varied in different Thymus hirtus sp.algeriensis methanol extracts and ranged from the lowest value of 7.08 detected for MT samples to the highest level of $8.81 \mathrm{mg}$ GAE/g attributed to MOK collection site (Table 2). Thyme aerial parts methanol extracts should to be rich in flavonoids with amounts varying from 1.08 to $2.25 \mathrm{mg} / \mathrm{g} \mathrm{RE}$ (Table 2). It should be mentioned that an increase of the phenolic metabolism in these plants may be related to the hard climate conditions (hot temperature, height solar exposure, dryness, short growing season).

The HPLC chromatographic analysis permitted the identification of eleven phenolic compounds in the methanolic extracts of Thymus hirtus sp. algeriensis, including eight phenolic acids ( caffeic acid, ferulic acid, gallic acid, hydroxyphenylic acid, vanillic acid, syringic acid, methyl galate, hydroxybis), and five flavonoids (tyrosin, rutin, (+)Catechin hydrate, vanillin, flavone). The results are shown in Table 2 and Figure 1. As can be seen data was obtained based on retention comparisons with phenolic acids and other polyphenols standards.

Among the mentioned phenolic compounds, hydroxybis was present in the largest amounts of $5581.77 \mu \mathrm{g} / \mathrm{g}$ followed by flavones and tyrosin. Much lower content was collected for ferulic acid. Whereas the lowest rate was obtained for $(+)$ - Catechin hydrate $(4.9 \mu \mathrm{g} / \mathrm{g})$. It is well-known that gallic acid is one of the major phenolics present in plants. Phenolic acids are usually implicated as natural antioxidants in fruits, vegetables and other plants. For example caffeic acid, ferulic acid, and vanillic acid are distributed in plants (Kingdom) [23]. Differences among phenolic compounds levels can be related to environmental conditions.

However, different results were obtained by Rachid [24] who reported the presence of five 8-c-benzylated flavonoids in Thymus hirtus sp. algeriensis extracts, 3 common flavones (apigenin, luteolin, diosmetin); 3 derived from these flavones and two derived from quercetine and kaempferol substituted by p-hydroxybenzyl.

The results obtained by GC/MS analysis of the essential oils are summarized in Table 3 where the compounds are 
Table 2 Major of phenolic compounds (\% of total) identified in Thymus algeriensis methanolic extract by HPLC

\begin{tabular}{|c|c|c|c|c|}
\hline \multirow[t]{2}{*}{ Compounds } & \multicolumn{3}{|c|}{ Content $(\mu \mathrm{g} / \mathrm{g}$ of dry plant material weight) } & \multirow[t]{2}{*}{ Approximate RT (min) } \\
\hline & $\overline{\mathrm{MT}^{\mathrm{a}}}$ & $M G^{a}$ & MOK $^{\mathrm{a}}$ & \\
\hline \multicolumn{5}{|l|}{ phenolic acids } \\
\hline Hydroxyphenyl acetic acid & $914.26 \pm 3.42$ & $2053.42 \pm 532.2$ & $n d^{b}$ & 2.425 \\
\hline gallic acid & $723.19 \pm 4.1$ & $744.72 \pm 12.1$ & $2780.57 \pm 492.1$ & 6.0 \\
\hline syringic acid & $119.31 \pm 4.2$ & $148.45 \pm 33.3$ & - & 14.35 \\
\hline Ferulic acid & $250.18 \pm 3.2$ & $41.64 \pm 6.2$ & $4657.94 \pm 840.1$ & 24.66 \\
\hline Methyl galate & $\mathrm{Nd}$ & $229.84 \pm 99.2$ & nd & 3.61 \\
\hline Vanillic acid & $1189.39 \pm 973.3$ & $614.72 \pm 41.2$ & nd & 15.96 \\
\hline Hydroxybis & $132.2 \pm 0.3$ & $5581.77 \pm 531.7$ & nd & 3.69 \\
\hline \multicolumn{5}{|l|}{ flavonoids } \\
\hline Tyrosin & $5013.06 \pm 934.1$ & $59.48 \pm 3.9$ & nd & 5.85 \\
\hline flavone & $128.6 \pm 0.4$ & $65.65 \pm 9.6$ & $5512.01 \pm 372.2$ & 9.16 \\
\hline Vanillin & $1079.26 \pm 57.1$ & $126.08 \pm 15.8$ & nd & 17.56 \\
\hline (+)- Catechin hydrate & $18.01 \pm 0.22$ & $4.9 \pm 0.7$ & nd & 19.68 \\
\hline Rutin & $609.62 \pm 0.6$ & $88.54 \pm 2.8$ & nd & 23.65 \\
\hline
\end{tabular}

Plant codes are indicated in Table $1 ;{ }^{b}$ nd: not detected. Values are means \pm SD of three independent replicates from two different samples of each collection sites $(n=6)$.

listed in order of their retention index on the HP-5MS column. Determination of the percentage composition of the samples was based on peak area normalization. It is depicted in this table that the chemical composition of Tunisian thyme extracts is characterised by its richness and its variety. Indeed, the number of products in the essential oils is 25 components and the composition of Thymus essential oils from three different localities, amounting to a total percentage of $77.75,77.16$, and $92.01 \%$, in Gafsa, Kairouan and Tamerza, respectively.

The oil yield of Thymus hirtus sp. algeriensis collected in Tamerza (Tozeur) is $10.82 \%(\mathrm{v} / \mathrm{w})$; the main components are terpinen-4-ol (33.34\%) and 1.8-cineole (14.12\%). Linalool (18.05\%) and camphor (13.03\%) are the most abundant component in Thymus hirtus sp. algeriensis oil collected in Gafsa.

The oil yield of Thymus hirtus sp. algeriensis collected in Kairouan is $5.75 \%$ and the major components are 1.8cineole (19.96\%) and camphor (19.20\%). A similar result was previously described by ElHadj Ahmed [27] who have found that the chemical composition of Thymus hirtus sp. algeriensis resulted in the identification of 25 compounds with a dominance of oxygen-containing monoterpenes, the main constituents were linalool (17.62\%) and camphor (13.82\%), whereas Ben El Hadj Ali [28] showed that camphor characterized few populations from the semi-arid zone of Tunisia.

The essential oil was characterized by very high percentage of monoterpenes and especially the oxygenated ones (29.76-59.53\%), which constituted the predominant class as was previously found for Thymus hirtus $s p$. algeriensis [7].
The monoterpene fractions presented the lowest level for the collection of Gafsa which is located in the semi-arid locality, increased for the samples collected in the semiarid locality Kairouan and reached the highest percentages in the arid sites, located in high altitudes, Tamerza.

The sesquiterpenes were also represented mainly by oxygenated sesquiterpenes (8.32\% and $35.54 \%)$ in contrast to what has been observed by Ben El Hadj Ali [28], where the amount of oxygenated sesquiterpenes did not exceed $4.6 \%$ of the total essential oil of Thymus hirtus $s p$. algeriensis. in fact; samples of Gafsa and Kairouan showed the lowest proportions (8.32\% and 35.54\%), respectively. MT is remarkable because it includes oils containing the terpenic oxide like 1,8-cineole, and monoterpenic alcohol such as terpinen-4-ol and borneol. The analyzed data illustrated significant differences in the amount of some compounds such as $\rho$-cymene (3.22-12.43\%), 1, 8-cineole (3.45-19.96\%), linalool (18.05\%), terpinen-4-ol (33.34\%), camphor (2.16-19.20\%), and bornyl acetate (5.41-11.67\%) in thyme harvested in different regions.

Thus, the Thymus hirtus sp. algeriensis oil analysis revealed that the major components were $\rho$-cymene, 1,8-cineole, linalool, terpinen-4-ol, bornyl acetate and camphor (a bornane derivative). Some components are currently encountered in all species whatever at variable amounts. It concerns monoterpenics phenols (thymol and carvacrol), its monoterpenics hydrocarbures ( $\rho$-cymene and $\gamma$-terpinene), oxygenated monoterpenes (borneol and linalool), terpinen-4-ol and 1, 8-cineole [29]. In agreement with our findings, Fatiha [30] obtained a similar result, except for some components like camphor (27.7\%) and $\alpha$-pinene (20.5\%). The essential oil of Thymus hirtus $s p$. 


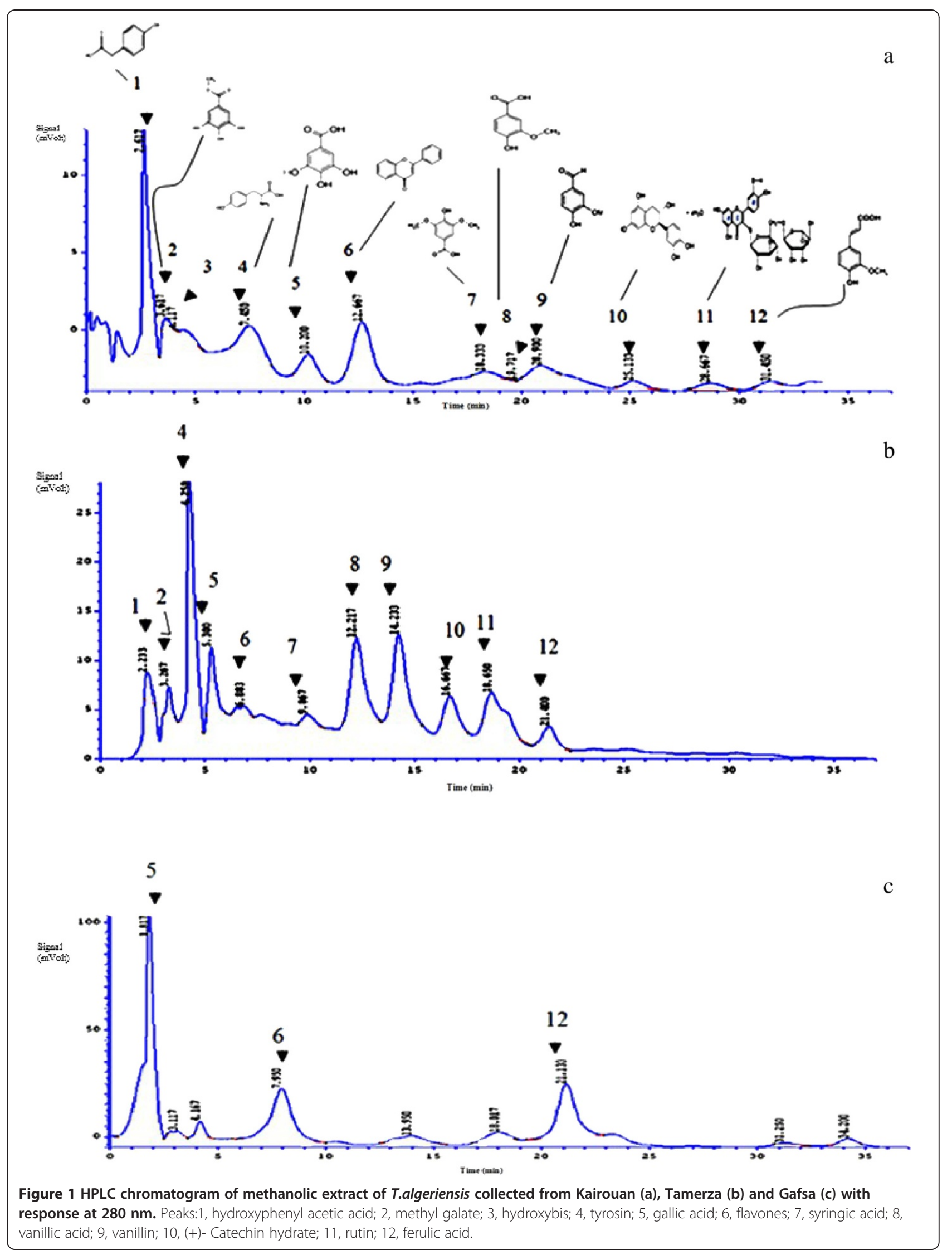


Table 3 Essential oil composition of aerial parts of Thymus algeriensis, cultivated in different locations

\begin{tabular}{|c|c|c|c|c|c|c|}
\hline \multirow[t]{2}{*}{ No. } & \multirow[t]{2}{*}{$\mathrm{Rl}^{\mathrm{a}}$} & \multirow[t]{2}{*}{ Components $^{\mathrm{b}}$} & \multicolumn{3}{|c|}{ Peak area (\%) } & \multirow{2}{*}{$\begin{array}{l}\text { Identificatior } \\
\text { methods }^{d}\end{array}$} \\
\hline & & & $\overline{M G^{c}}$ & $\mathrm{MT}^{\mathrm{c}}$ & $\overline{\text { MOK }^{c}}$ & \\
\hline 1 & 939 & a-pinene & - & 2.55 & 3.74 & GC-MS \\
\hline 2 & 946 & Camphene & - & 1.49 & 1.83 & GC-MS \\
\hline 3 & 975 & Sabinene & - & 1.56 & - & GC-MS-RT \\
\hline 4 & 979 & $\beta$-pinene & - & 1.44 & 1.14 & GC-MS \\
\hline 5 & 1017 & a-terpinene & 1.18 & 1.69 & - & GC-MS-RI \\
\hline 6 & 1025 & $\rho$-cymene & 3.22 & 12.43 & - & GC-MS-RI \\
\hline 7 & 1029 & Limonene & - & - & 0.78 & GC-MS \\
\hline 8 & 1031 & 1,8-cineole & 3.45 & 14.12 & 19.96 & GC-MS \\
\hline 9 & 1060 & y-terpinene & 2.43 & 4.30 & - & GC-MS \\
\hline 10 & 1070 & trans-sabinene hydrate & - & 1.21 & - & GC-MS-CAS\#\# \\
\hline 11 & 1089 & Terpinolene & 1.35 & 1.25 & - & GC-MS \\
\hline 12 & 1097 & Cis-sabinene-hydrate & - & 1.15 & - & GC-MS-CAS\# \\
\hline 13 & 1098 & Linalool & 18.05 & - & - & GC-MS \\
\hline 14 & 1146 & Camphor & 13.03 & 2.16 & 19.20 & GC-MS \\
\hline 15 & 1165 & Pinocarvone & - & - & 0.97 & GC-MS \\
\hline 16 & 1169 & Borneol & - & 2.78 & 7.64 & GC-MS \\
\hline 17 & 1176 & 4-carvomenthenol & 11.2 & - & 3.72 & GC-MS \\
\hline 18 & 1177 & Terpinen-4-ol & - & 33.34 & - & GC-MS \\
\hline 19 & 1205 & Verbenone & - & - & 1.06 & GC-MS \\
\hline 20 & 1289 & Bornyl acetate & 5.41 & 8.34 & 11.67 & GC-MS \\
\hline 21 & 1420 & $\beta$-caryophyllene & - & - & 0.85 & GC-MS \\
\hline 22 & 1511 & y-cadinene & 1.21 & - & - & GC-MS \\
\hline 23 & 1578 & Spathulenol & 2.80 & - & - & GC-MS \\
\hline 24 & 1582 & Caryophyllene oxide & 2.09 & 2.20 & 4.60 & GC-MS \\
\hline 25 & 1590 & Viridiflorol & 11.71 & - & - & GC-MS \\
\hline \multicolumn{7}{|c|}{ Chemical classes } \\
\hline & & Monoterpene hydrocarbons & 8.18 & 26.71 & 8.46 & \\
\hline & & Oxygenated monoterpenes & 51.14 & 29.76 & 59.53 & \\
\hline & & Sesquiterpene hydrocarbons & 1.21 & - & 0.85 & \\
\hline & & Oxygenated sesquiterpenes & 16.6 & 35.54 & 8.32 & \\
\hline & & Total identified, \% & 77.75 & 92.01 & 77.16 & \\
\hline & & Essential Oil Yield (\%) & 2.36 & 10.82 & 5.75 & \\
\hline
\end{tabular}

${ }^{\mathrm{a}} \mathrm{Rl}$ (retention index) measured relative to $\mathrm{n}$-alkanes (C10 -C15); ${ }^{\mathrm{b}}$ Components listed in order of their retention index on HP on HP-5 column, ${ }^{\mathrm{C}} \mathrm{Plant}$ codes; ${ }^{\mathrm{d}} \mathrm{GC}-\mathrm{MS}$ : identification based on a high match of mass spectra; ${ }^{\mathrm{e} T \mathrm{RT}}$ : retention time compared with those reported in the literature [25]; ${ }^{f} \mathrm{CAS} \#=\mathrm{Chemical}$ Abstracts service reference number compared with those reported in the literature [26].

algeriensis collected from Khedara and Fatoum Souda (Algeria) had the same major components as our samples, but Algerian Thymus oils are richer in $\alpha$-pinene (27.14$25.52 \%)$ than in camphor (8.77-8.45\%), also in sabinene (5.25-5.61\%) and in $\beta$-pinene (2.66-3.12\%) [31].

Thymol was not detected in all regions described in this research and it was reported at low amounts $(<1 \%)$ in populations from the same bioclimatic zone described by Zouari [11].
Biogenetic precursor of the phenols were present in a 3.22-12.43\% range $\rho$-cimene and $2.43-4.3 \% \gamma$-terpinene. As can be seen in Table 3, Viridiflorol was detected with high rate $(11.71 \%)$ in a population from the inferior arid zone (MG). A similar result was previously described by Ben El Hadj Ali [28].

Terpinen-4-ol was absent in MG and MOK, except for MT which was distinguished by a high proportion of this constituent (33.34\%). 
Many factors can be responsible of the variability of thyme extracts chemical composition. The most important are the climate, the soil, the harvest period and the method of preservation and extraction [32-35]. Genetic factors [36] and vegetative cycle [11] can also influence this variability.

In the radical form, DPPH had an absorbance at $517 \mathrm{~nm}$ which disappeared after acceptance of an electron or hydrogen radical from an antioxidant compound to become a stable diamagnetic molecule [37].

The method is used to evaluate the antioxidant properties of the thyme methanol extracts and essential oils in comparison with those of known natural and synthetic antioxidants, BHT.

The BHT showed the highest radical scavenging activity, while the thyme methanolic extracts and essential oils demonstrated much lower activity. Table 4 shows the percentage inhibition of free radicals by thyme extracts due to hydrogen donation from the antioxidants. The order of antioxidant activity of thyme extract was: $\mathrm{BHT}>\mathrm{MT}>\mathrm{MG}>\mathrm{MOK}$. The essential oils have an activity in the order: $\mathrm{BHT}>\mathrm{MT}>\mathrm{MOK}>\mathrm{MG}$.

These results concur with other researchers who have also reported that another species of thymus like Thymus satureidoides had the best antioxidants activities (74.50\%), nevertheless inferior to those of BHT (98.59\%), and the same thing for $T$. vulgaris with an antioxidant activity of about $57.46 \%$ [38]. In disagreement with our result. Gianni [39] found that the percentage inhibition of T.vulgaris $(90.9 \pm 0.64 \%)$ is superior to those of BHA $(68.74 \pm 0.61 \%)$. Essential oil showed the lowest scavenging effect on DPPH. Our results are in accordance with other investigators [40] who have also reported that the Thymus capitatus oil had a weak antioxidant activities, essential oil concentrations are 12.0; 15.0; 25 and $62.5 \mu \mathrm{g} / \mathrm{ml}$ which had the scavenging effect on $\mathrm{DPPH}$, respectively, $27 \pm 2.0,30 \pm 0.7$ and $40 \pm 0.3 \%$. The MT extract showed the highest radical scavenging activity (RSA) among all tested methanol extracts, followed by MG and MOK. In contrast, MOK showed the lowest RSA values (80\%) at $50 \mu \mathrm{g} / \mathrm{ml}$.

Although the DPPH radical scavenging ability of the extracts and essential oils were significantly lower than those of BHT, it was evident that the extracts did show the proton-donating ability and could serve as free radical inhibitors or scavengers, acting as possibly as primary antioxidants.

In the case of $\beta$-carotene /linoleic acid test results, the presence of thyme extract can hinder the extent of $\beta$-carotene bleaching by acting on the linoleate-free radical and other free radicals formed in the system. Accordingly, the absorbance decreased rapidly in samples without antioxidant whereas, in the presence of MT methanolic extract, they retained their color and thus absorbance, for a longer time. Figure 2 shows the absorbance of the total thyme methanolic extracts and essential oils with the BHT. The antioxidant power decreased in the order $\mathrm{BHT}>\mathrm{MT}>\mathrm{MOK}>\mathrm{MG}$ for methanol extracts and $\mathrm{BHT}>\mathrm{MOK}>\mathrm{MG}>\mathrm{MT}$ for essential oils. The decreasing of absorbance of $\beta$-carotene with or without extract (or essential oils) is measured with time. The extract (or essential oils) avoid the bleaching of $\beta$-carotene with comparison with the control. The absorbance of the control demonstrate a decreasing after $15 \mathrm{~min}$. Aerial part oils had the weak antioxidant activities, and its inhibition were of about third of that of BHT, in contrast to the methanolic extracts of the same plants, which presented activities comparable of that of BHT. But for essential oil of MT the rate is slow to maintain the absorbance at 0.04 after $35 \mathrm{~min}$.

The double bonds of $\beta$-carotene and saturated fatwere attaqued by radicals. Results clearly demonstrated that extracts and essential oils of Thymus hirtus sp. algeriensis delayed the degradation of $\beta$-carotene.

Proton radical scavenging is an important attribute of antioxidants ABTS, a protonated radical, has characteristic absorbance maxima at $743 \mathrm{~nm}$ which decreases with scavenging of the proton radicals [41]. The antioxidant activity of thyme extracts from methanol was evaluated by means of ABTS assay, and the results are shown in Table 4. Apparently, the antioxidant activity of thyme extracts was found to be in the order: MT > MOK > MG. Of the three samples tested, MT had the highest ABTS values. The results obtained suggest that the higher the polarity of thyme extracts, the stronger is the antioxidant activity.

Table 4 Comparison of the content of phenolic and flavonoid and antioxidant activity of T.algeriensis extracts ${ }^{\mathrm{a}}$ suitable for medical uses

\begin{tabular}{|c|c|c|c|c|c|c|c|c|}
\hline \multirow[t]{2}{*}{ Sample } & \multirow{2}{*}{$\begin{array}{l}{ }^{\mathrm{b}} \mathrm{TPC} \\
\left(\mathrm{mg} \mathrm{GAE} / \mathrm{g} \mathrm{dw}{ }^{\mathrm{d}}\right)\end{array}$} & \multirow{2}{*}{$\begin{array}{l}{ }^{\mathrm{e}} \mathrm{TF} \\
(\mathrm{mg} \mathrm{RE} / \mathrm{g} \mathrm{dw})\end{array}$} & \multicolumn{2}{|c|}{ DPPH Inhibition \% } & \multicolumn{2}{|c|}{ ABTS Inhibition \% } & \multicolumn{2}{|c|}{$\beta$-Carotene bleaching inhibition \% } \\
\hline & & & M.E $E^{g}$ & E. $O^{h}$ & M.E & E.O & M.E & E.O \\
\hline$\overline{\mathrm{MT}}$ & $7.08 \pm 0.7$ & $1.08 \pm 0.8$ & $93 \pm 0.06$ & $85 \pm 0.57$ & $75 \pm 0.72$ & $16 \pm 0.12$ & $31 \pm 0.91$ & $10 \pm 0.52$ \\
\hline MG & $8.7 \pm 0.59$ & $1.95 \pm 0.4$ & $84 \pm 0.034$ & $82 \pm 0.52$ & $50 \pm 0.96$ & $8 \pm 0.7$ & $25 \pm 0.08$ & $4 \pm 0.44$ \\
\hline MOK & $8.81 \pm 0.12$ & $2.25 \pm 0.43$ & $81 \pm 0.26$ & $83 \pm 0.1$ & $22 \pm 0.9$ & $19 \pm 0.33$ & $50 \pm 0.12$ & $5 \pm 0.71$ \\
\hline $\mathrm{BHT}$ & & & $93 \pm 0.25$ & $86 \pm 0.62$ & $86 \pm 0.37$ & $19 \pm 0.81$ & $36 \pm 0.66$ & $36 \pm 0.66$ \\
\hline
\end{tabular}

${ }^{a}$ Values are the mean \pm standard deviation $(n=3) ;{ }^{b}$ TPC:Total Phenolic Compounds; ${ }^{c}$ GAE. Gallic acid equivalents; ${ }^{d}$ Dry weight basis of the original sample of plant parts; ${ }^{\mathrm{e}} \mathrm{TF}$ : Total Flavonoids; ${ }^{\mathrm{f}} \mathrm{RE}$. Rutin equivalents; ${ }^{\mathrm{g}}$ Methanolic extracts; ${ }^{\mathrm{h}}$ Essential oils. 

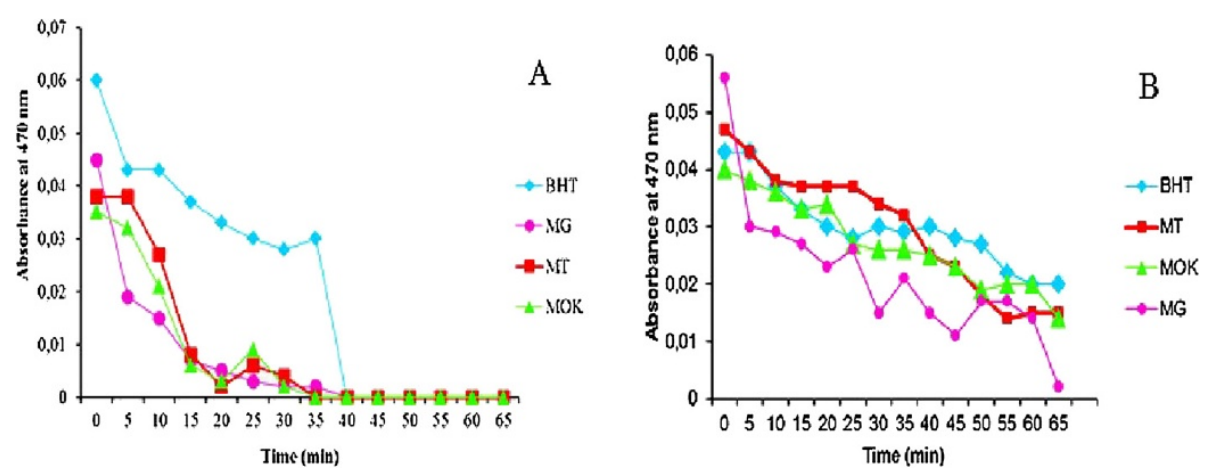

Figure 2 The antioxidant activity of essential oils (A) and methanolic extracts (B) of thymus hirtus sp. algeriensis using the $\beta$-carotene bleaching, BHT $(\bullet)$, MG $(\bullet)$, MOK $(\Delta)$, MT $(\bullet)$.

To establish the relationship between phenolic compounds and the antioxidant capacity, linear correlation coefficients were calculated and results are shown in Table 5. Positive significant $(p<0.05)$ correlations confirmed between vanillic acid, tyrosin, vanillin, $(+)$ Catechin hydrate, rutin and the DPPH assay proved the significance of these compounds in the scavenging power of Thymus hirtus sp. algeriensis extracts. Similarly, vanillic acid showed a positive significant $(p<0.05)$ correlation with the ABTS scavenging activity. On the contrary, total phenolic and total flavonoid contents illustrated negative significant $(p<0.05)$ correlations with the DPPH test. Previous investigations on several Lamiaceae species such as Rosmarinus officinalis [42], Thymus vulgaris [43], Marrubium globosum [44], Salvia officinalis, S. verbenaca, S. aegyptiaca and S. argentea [45] demonstrated close correlations between polyphenolics and antioxidant

Table 5 Correlation coefficients between phenolic contents versus the antioxidant capacities determined by DPPH, ABTS and $\beta$-carotene bleaching

\begin{tabular}{llll}
\hline & DPPH & ABTS & $\beta$-carotene bleaching \\
\hline Hydroxyphenyl acetic acid & 0.200 & 0.470 & -0.940 \\
Gallic acid & -0.700 & -0.890 & 0.970 \\
Syringic acid & 0.500 & 0.780 & -1.000 \\
Ferulic acid & -0.700 & -0.860 & 0.980 \\
Methyl galate & -0.300 & 0.030 & -0.690 \\
Vanillic acid & 1.000 & 1.000 & -0.740 \\
Hydroxybis & -0.300 & 0.050 & -0.700 \\
Tyrosin & 1.000 & 0.850 & -0.300 \\
Flavone & -0.700 & -0.880 & 0.980 \\
Vanillin & 1.000 & 0.900 & -0.390 \\
(+)- Catechin hydrate & 1.000 & 0.960 & -0.530 \\
Rutin & 1.000 & 0.910 & -0.410 \\
Total phenolic content & -1.000 & -0.880 & 0.340 \\
Total flavonoid content & -1.000 & -0.950 & 0.520 \\
\hline
\end{tabular}

activity, which could support the effectiveness of these compounds as free radical-scavengers and antioxidants. The good relationship between the less represented phenolic compound namely $(+)$ - Catechin hydrate and the DPPH assay (Table 5) may support the contribution of minor compounds in synergy with major compounds to the resulting antioxidant activity.

The antibacterial activity of essential oil was tested against six different genera of bacteria namely E.coli, P. ae, S. e, S. $a, B$. s and L. monocytogynes. The essential oil from Thymus hirtus sp. algeriensis of 3 regions in Tunisia has a considerable inhibitory effect on all tested bacteria; it demonstrated different degrees of growth inhibition. Results of antibacterial activity of Thymus hirtus sp. algeriensis oils are summarized in Table 6 . Results clearly demonstrated that MOK oil showed the lowest antibacterial activity among the tested oils; with i.z. (inhibition zone) $9.0-36.0 \mathrm{~mm}$; MT and MG possessed almost the same activity with i.z.30.0-74.0 mm. Penicillin showed activity with i.z.0-10 $\mathrm{mm}$ for L. monocytogynes. The antibacterial activity of Thymus hirtus $s p$. algeriensis oils tested was found to have an effect on the grampositive bacteria S. a ATCC 52923 and B. s 106 which seemed to be more easily inhibited than the Gramnegative bacteria, namely E. coli GM 109, P. ae and S. e ATCC 502. An important characteristic of this finding totally agrees with the observation derived from studies with essential oils from other thyme species [46].

Soković [47] reported the effect of essential oil of T. vulgaris on Gram (+) bacteria as S.a, B.s, with same i.z (28 mm), instead, Bektas [48] reported that T. hyemalis, essential oil showed weaker antimicrobial activity, he found that in the presence of this sample, no activity was observed against P.ae and L.monocytogynes, but a great effect on Gram (+) bacteria as B.s, B.c and S.a with i.z, respectively, $17.30 \pm 0.64,20.50 \pm 0.46$ and $15.00 \pm$ $0.74 \mathrm{~mm}$. It is obvious that Gram-negative bacteria were found to be sensitive to Thymus hirtus sp. algeriensis oils, despite that they have an outer layer surrounding their cell 
Table 6 Antibacterial activity of the essential oil of Thymus algeriensis

\begin{tabular}{|c|c|c|c|c|c|c|c|c|c|c|c|c|}
\hline \multirow[t]{3}{*}{ Micoorganisms } & \multicolumn{6}{|c|}{ Essential oil } & \multicolumn{6}{|c|}{ Antibiotics } \\
\hline & \multicolumn{2}{|c|}{ MOK } & \multicolumn{2}{|l|}{ MT } & \multicolumn{2}{|l|}{ MG } & \multicolumn{2}{|c|}{$\mathrm{SM}^{\mathrm{C}}(10 \mu \mathrm{g} / \mu \mathrm{l})$} & \multicolumn{2}{|c|}{$\mathrm{CP}^{\mathrm{d}}(30 \mu \mathrm{g} / \mu \mathrm{l})$} & \multicolumn{2}{|c|}{$\mathrm{PC}^{\mathrm{e}}(30 \mu \mathrm{g} / \mu \mathrm{l})$} \\
\hline & $\mathrm{DD}^{\mathrm{a}}$ & $\mathrm{MIC}^{\mathbf{b}}$ & $\mathrm{DD}$ & MIC & $\mathrm{DD}$ & MIC & $\mathrm{DD}$ & MIC & $\mathrm{DD}$ & MIC & $\mathrm{DD}$ & MIC \\
\hline Staphylococcus aureus ATCC 25923 & 22 & 4.50 & 63 & 1.50 & 63 & 1.70 & 15 & 20.00 & 33 & 2.00 & $\mathrm{nt}$ & $\mathrm{nt}$ \\
\hline Bacillus subtilis 166 & 36 & 5.50 & 30 & 4.00 & 25 & 4.50 & 22 & 5.00 & 20 & 1.00 & nt & $\mathrm{nt}$ \\
\hline Salmonella enteridis ATCC 502 & 9 & 22.00 & 43 & 2.00 & 65 & 1.50 & 13 & 20.00 & 27 & 1.50 & nt & $\mathrm{nt}$ \\
\hline E.coli GM 109 & 30 & 4.00 & 50 & 1.80 & 30 & 4.20 & 15 & 23.00 & 27 & 1.50 & nt & $\mathrm{nt}$ \\
\hline Pseudomonas aeruginosa & 9 & 22.00 & 74 & 0.90 & 30 & 4.50 & 17 & 20.00 & 28 & 1.50 & $\mathrm{nt}$ & $\mathrm{nt}$ \\
\hline Listeria monocytogynes & 20 & 7.50 & 45 & 2.00 & 32 & 4.00 & $n t^{f}$ & nt & nt & nt & 10 & 22.00 \\
\hline
\end{tabular}

${ }^{\mathrm{a} D D}$, disc diffusion method as recommended by NCCLS. Diameter of zone of inhibition $(\mathrm{mm})$ including disk diamater of $6 \mathrm{~mm},{ }^{\mathrm{b}} \mathrm{MIC}$, minimum inhibitory concentration; Value given as $\mathrm{mg} / \mathrm{ml}$ (for the essential oil) and as $\mu \mathrm{g} / \mathrm{ml}$ (for antibiotics); ${ }^{\mathrm{C}} \mathrm{SM}$, Chloramphenicol $(30 \mu \mathrm{g} / \mu \mathrm{l}) ;{ }^{\mathrm{d}} \mathrm{CP}, \mathrm{Streptomycin}(10 \mu \mathrm{g} / \mu \mathrm{l}) ;{ }^{\mathrm{e}} \mathrm{PC}$, Penicillin $(30 \mu \mathrm{g} / \mu \mathrm{l}) ;{ }^{\mathrm{f}} \mathrm{nt}$, not tested.

wall that act as permeability barrier, limiting the access of hydrophobic compounds [49]. MT was more effective in inhibiting all tested bacteria, than those of MG and MOK. The microorganism E.coli, which is already known to be multi-resistant to drugs, was susceptible to different antibiotics, had its growth inhibited by essential oil of Thymus hirtus sp. algeriensis (37-63 $\mathrm{mm}$ ), this was due to the loss of resistance, probably because of the loss of plasmids. Our results are comparable to those of Giweli [50] who found that the oil of a Mediterranean species satureja thymbra (family Lamiacea) showed bacteriostatic activity at $0.001-0.1 \mathrm{mg} / \mathrm{mL}$ and was bactericidal at $0.002-0.2 \mathrm{mg} / \mathrm{mL}$; fungistatic effects at $0.001-0.025 \mathrm{mg} / \mathrm{mL}$ and fungicidal effects at $0.001-0.1 \mathrm{mg} / \mathrm{mL}$. From our results it can be seen that $\mathrm{MIC}_{\mathrm{s}}$ are generally lower for the essential oil investigated in this research. Thymus hirtus sp. algeriensis essential oil showed slightly higher antibacterial activity than Chloramphenicol, Ampicillin and Streptomycin.

Essential oil of thyme can have preventive effect by the means of antioxidants properties of its components. It seems evident that there is a relationship between the high activity of Thymus hirtus sp. algeriensis oils and the presence of monoterpene alcohol, such as terpinen-4-ol and linalool.

Earlier reports had claimed the effect of cyclic monoterpenes. This observation was consistent with a previous report, where 1,8-cineole and borneol were found to have a moderate antibacterial activity [51]. In disagreement with this finding, previous results showed that greater antimicrobial potential could be ascribed to the oxygenated terpenes, especially phenolic compounds. The antibacterial property of mostly essential oils is suspected to be associated with the high percentage of caryophyllene oxide, $\alpha$-pinene, and $\beta$-pinene, and 1,8cineole, which are known to possess strong antibacterial activity [52]. Andrews [53] found that $\alpha$-pinene (2 mM) disrupted the cytoplasmic membranes of Saccharomyces cerevisiae and the Gram-positive organism Bacillus thuringiensis, but that Gram-negative bacteria were more resistant to terpenes. $\beta$-pinene inhibited respiration at the cytochrome b portion of the electron transport chain of yeast cells [54].

It appears that the small molecular weight of essential oil compounds allows them to penetrate the inner membrane of Gram-negative bacteria [55]. It can be seen that the antibacterial activity of MG oil responded to great percentage of linalool, camphor, terpinen-4-ol and Viridiflorol. These results concur with other researchers who have also reported that linalool has a strong effect against a number of different bacteria [56]. In disagreement a previous result corroborated that the essential oil from Thymus zygis containing 39\% linalool had no bacteriostatic activity against isolates of $E$. coli unless thymol or carvacrol was also present. The oil of MOK exhibited moderate activity against S. a ATCC 25923 and L. monocytogynes $\left(\mathrm{MIC}_{\mathrm{s}}, 4.5\right.$ to $7.5 \mathrm{mg} / \mathrm{ml}$ ) and slightly lower antibacterial effect were observed against $P$. ae and S. e ATCC $502(22.00 \mathrm{mg} / \mathrm{ml})$.

It is extremely important to point out that, antibacterial effects of essential oils in Thymus hirtus sp. algeriensis are strictly related with the presence of 1.8-cineole which is present in great proportion in MT (14.12\%) and MOK (19.96\%).

The above screening result enumerates the existing potential of plant essential oil to be used as suitable constituent in pharmaceuticals and food preservatives of plant origin for treating plant and animal diseases caused by pathogens and food spoiling microorganisms.

\section{Conclusion}

The beneficial effects of flavonoids in cancer therapy have often been linked to their ability to act as antioxidants, which includes their reducing capacities and ROS-scavenging capabilities.

\section{Abbreviations}

HPLC: Height pressure liquid chromatography; DPPH: 2, 2-diphenyl-1picrylhydrazyl; ABTS: 2, 2-Azinobis-3-ethylbenzothiazoline-6-sulfonate; BHT: Butylatedhydroxytoluene; FC: Folin-Ciocalteu; $\mathrm{MoO}^{4+}$ : Molybdenum 
oxide; GAE: Gallic acid equivalents; $\mathrm{Na}_{2} \mathrm{CO}_{3}$ : Sodium bicarbonate; RE: Rutin equivalents; Abs: Absorbance; $\mathrm{K}_{2} \mathrm{~S}_{2} \mathrm{O}_{8}$ : Potassium persulfate; BHA: Butylatedhydroxyanisol; RSA: Radical scavenging activity; $s$. a: staphylococcus aureus; B.s: Bacillus subtilis; E. coli: Escherichia coli; P. ae: Pseudomonas aeruginosa; S.e: Salmonella enteredis; L. monocytogynes: Listeria monocytogynes.

\section{Competing interests}

The authors declare that they have no competing interests.

\section{Authors' contributions}

GF, BFM participated in the design of the study and performed the statistical analysis. GF, BFM and MM have been involved in drafting the manuscript and revising it critically for important intellectual content, LA have given final approval of the version to be published. All authors read and approved the final manuscript.

\section{Acknowledgment}

We thank Mr Hamdi Lazhar, Engineer and Director of Bouhedma Natural Park for the identification of the harvested plant used in this study. We are grateful to Dr Chokri Messaoud (INSAT) for his help in the GC/MS analyses.

\section{Author details}

'Laboratory of Biochemical and Molecular Biology, Faculty of Science of Bizerte, University of Carthage, Bizerte, Tunisia. ${ }^{2}$ Higher Institute of Technological Studies (ISET), Mogran, Zaghouan, Tunisia.

Received: 4 April 2014 Accepted: 3 July 2014

Published: 14 July 2014

\section{References}

1. Pottier-Alapetite G: Flore de la Tunisie. Angiospermes. Dicotylédones. Gamopétales, Vol II. Tunis (Tunisia). Tunisia: Imprimerie officielle de la République Tunisienne; 1981:809-811.

2. Morales R: Studies of the genus Thymus L. Lamiales. Newsletter 1996, 4:6-8.

3. Ben El Hadj Ali I, Arbi G, Boussaid M: Effect of habitat fragmentation on the genetic structure of the gynodioecious Thymus algeriensis Boiss et Reut. (Lamiaceae) in Tunisia. Plant Biosystem 2010, 148(2):217-226.

4. Soković MD, Vukojević J, Marin PD, Brkić DD, Vajs V, van Griensven LJLD: Chemical composition of essential oils of Thymus and Mentha species and their antifungal activities. Molecules 2009, 14:238-249.

5. Sthal-Biskup E, Saez F: Thyme: the genus Thymus (Medicinal and Aromatic Plants-Industrial Profiles). J Essent Oil Res 2002, 330:415-848.

6. Le Floc'h E: Contribution à une étude ethnobotanique de la flore tunisienne, Edited by publication Scientifique tunisiennes. Imprimerie Officielle de la République Tunisienne; 1983:402.

7. Zouari N, Fakhfakh N, Zouari S, Bougatef A, Neffati M, Ayadi MA: Chemical composition, angiotensin I-converting enzyme inhibitory, antioxidant and antimicrobial activities of essential oil of Tunisian Thymus algeriensis Boiss. et Reut. (Lamiaceae). Food Bioprod Process 2011, 89:257-265.

8. Amarti F, Satrani B, Aafi A, Ghanmi M, Farah A, Aberchane M, El Ajjouri M, El Antry $\mathrm{S}$, Chaouch A: Composition chimique et activité antimicrobienne des huiles essentielles de Thymus capitatus et de Thymus bleicherianus du Maroc. Phytother Res 2008, 6:342-347.

9. Teimouri M: Antimicrobial activity and essential oil composition of Thymus daenensis Celak from Iran. J Med Plants Res 2012, 6:631-635.

10. Zouari N, Ayadi I, Fakhfakh N, Rebai A, Zouari S: Variation of chemical composition of essential oils in wild populations of Thymus algeriensis Boiss. Et Reut., a North African endemic species. Lipids Health Dis 2012, $11: 28$.

11. Mateos R, Espartero JL, Trujillo M, Ríos JJ, León-Camacho M, Alcudia F, Cert A: Determination of phenols, flavones, and lignans in virgin olive oils by solid-phase extraction and high-performance liquid chromatography with diode array ultraviolet detection. J Agric Food Chem 2001, 49:2185-2192.

12. Singleton VL: Tannins and the Qualities of Wines. In Plant Polyphenols Synthesis, Properties, Significance. Edited by Hemingway RW, Laks PE. New York: Plenum Press; 1992:859-880.

13. Dewanto $V$, Wu X, Adom KK, Liu RH: Thermal pro- cessing enhances the nutritional value of tomatoes by increasing total antioxidant activity. J Agric Food Chem 2002, 50:3010-3014.
14. Bondet $\mathrm{V}$, Brand-Williams W, Berset $\mathrm{C}$ : Kinetics and mechanisms of antioxidant activity using the DPPH free radical method. Lebensur Wiss Technol 1997, 30:609-615.

15. Miller NJ, Rice-Evans C, Davies MJ, Gopinathan V, Milner A: A novel method of measuring antioxidant capacity and its application to monitoring the antioxidant status in premature neonates. Clin Sci 1993, 84(4):407-412.

16. Fukuzawa K, Inokami Y, Tokumura A, Terao J, Suzuki A: Rate constants for quenching singlet oxygen and activities for inhibiting lipid peroxidation and carotenoids and a-tocopherol in liposomes. Lip 1998, 33:751-756.

17. Pratt DE: Natural antioxidants of soybean and other oil-seeds. In Autoxidation in Food and Biological systems. Edited by Simic MG, Karel M. New York: Plenum Press; 1980:283-292.

18. Reis FS, Martins A, Barros L, Ferreira ICFR: Antioxidant properties and phenolic profile of the most widely appreciated cultivated mushrooms: a com-parative study between in vivo and in vitro samples. Food Chem Toxicol 2012, 50:1201-1207.

19. Rasoanaivo P, Ratsimamanga-Urverg S: Biological Evaluation of Plants with Reference to the Malagasy Flora. Antananarivo, Madagascar: Monograph for the IFS-NAPRECA Workshop on Bioassays; 1993:72-79.

20. Vlietinck AJ, Van Hoof L, Totté J, Lasure A, Vanden Berghe D, Rwangabo PC, Mvukiyumwami J: Screening of hundred Rewandese medicinal plants for antimicrobial and antiviral properties. J Ethnopharmacol 1995, 46:31-47.

21. Erdemoglu N, Ozkan S, Tosun F: Alkaloid profile and antibacterial activity of Lupinus angustifolius L. alkaloid extract. Phytochem Rev 2007, 6:197-201.

22. Larson RA: The antioxidants of higher plants. Phytochemistry 1988, 27:969-978.

23. Rachid M, Maurio J, Marie RV, Christine B, Bernard V: Five 8-C-benzylated flavonoids from Thymus hirtus (Labiateae). Phytochem 1995, 38(4):637-640.

24. Adams RP: Identification of Essential Oils Components by Gas Chromatography/quadrupole Mass Spectrometry. 4th edition. USA: Allured, Carol Stream, III; 2001.

25. Adams RP, Weyerstahl P: Cis- and trans-Sabinene hydrate: comparisons of quadrupole and ion trap mass spectra. Research letter. J Essent Oil Res 1992, 4:197-200.

26. Ahmed SB, Sghaier RM, Guesmi F, Kaabi B, Mejri M, Attia H, Laouini D, Smaali I: Evaluation of antileishmanial, cytotoxic and antioxidant activities of essential oils extracted from plants issued from the leishmaniasis-endemic region of Sned (Tunisia). Natur Product Res 2011, 25:1195-1201

27. Ben El Hadj Ali I, Zaouali Y, Bejaoui A, Boussaid M: Variation of the chemical composition of essential oils in Tunisian populations of Thymus algeriensis Boiss. et Reut. (Lamiaceae) and implication for conservation. Chem Biodivers 2010, 7:1276-1289.

28. Sthal-Biskup E: The chemical composition of Thymus oils: review of the literature 1960-1989. J Essent Oil Res 1991, 3:61-82.

29. Fatiha A, Badr S, Mohamed G, Abdellah F, Abderrahman A, Lotfi A Mustapha EA, Abdelaziz C: Composition chimique et activité antimicrobienne des huiles essentielles de Thymus algeriensis Boiss. \& Reut. et Thymus ciliatus (Desf.) Benth. Du Maroc. Biotechnol Agron Soci Envir 2010, 14:141-148.

30. Giordani R, Hadef $Y$, Kaloustian J: Compositions and antifungal activities of essential oils of some Algerian aromatic plants. Fitoterapia 2008, 79:199-203.

31. Johnson CB, Kazantzis A, Skoula M, Mitteregger U, Novak J: Seasonal, populational and ontogenic variation in the volatile oil content and composition of individuals of Origanum vulgare subsp. Hirtum, assessed by GC headspace analysis and by SPME sampling of individual oil glands. J Phytochem Anal 2004, 15(5):286-292.

32. Semiz G, Heijari J, Işik K, Holopainen JK: Variation in needle terpenoids among Pinus sylvestris L. (Pinaceae) provenances in Turkey. Biochem Sys Ecol 2007, 35:652-661.

33. Kupcinskiene $E$, Stikliene A, Judzentiene A: The essential oil qualitative and quantitative composition in the needles of Pinus sylvestris L. growing along industrial transects. Environ Pollut 2008, 155(3):481-491.

34. Dawidowicz AL, Czapczyńska NB, Wianowska D: Relevance of the Sea Sand Disruption Method (SSDM) for the Biometrical Differentiation of the Essential-Oil Composition from Conifers. Chem Biodiv 2013, 10(2):241-250.

35. Echeverrigary S, Agostini G, Atti-Serfini L, Paroul N, Pauletti GF, dos Santos $\mathrm{AC}$ : Correlation between the chemical and genetic relationships among commercial thyme cultivars. J Agric Food Chem 2001, 49:4220-4223. 
36. Matthäus $B$ : Antioxidant activity of extracts obtained from residues of different oil seeds. J Agric Food Chem 2002, 2002(50):3444-3452.

37. Bouhdid S, Idaomar M, Zhiri A, Baudoux D, Skali NS, Abrini J: Thymus essential oils: chemical composition and in vitro antioxidant and antibacterial activities. In Biochimie, Substances Naturelles et Environnement Congrès international de biochimie, Agadir, Maroc; 2006:9-12.

38. Gianni S, Silvia M, Mariavittoria M, Martina S, Stefano M, Matteo R, Renato B: Comparative evaluation of 11 essential oils of different origin as functional antioxidants, antiradicals and antimicrobials in food. Food Chem 2005, 91:621-632.

39. El Mokhtar EO, Julien P, Abdelhamid B, Pierre T, Belkheir H, Rachid S, Lhou $M$, Jean C: Chemical composition and antioxidant activity of essential oils and solvent extracts of Thymus capitatus(L.) Hoffmanns and link from Morocco. J Med Plants Res 2011, 5(24):5773-5778.

40. Mathew S, Abraham TE: In vitro antioxidant activity and scavenging effects of Cinnamum verum leaf extract assayed by different methodologies. Food Chem Toxicology 2006, 44:198-206.

41. Almela L, Sinchez M, Fernindez J, Roca M, Rabe V: Liquid chromatograpic-mass spectrometric analysis of phenolics and free radical scavenging activity of rosemary extract from different raw material. J Chromatogr A 2006, 1120(1-2):221-229.

42. Chizzola R, Michitsch H, Franz C: Antioxidative properties of Thymus vulgaris leaves: comparison of different extracts and essential oil chemotypes. J Agric Food Chem 2008, 56:6897-6904.

43. Sarikurkcu C, Tepe B, Daferera D, Polissiou M, Harmandar M: Studies on the antioxidant activity of the essential oil and methanol extract of Marrubium globosum subsp. globosum (lamiaceae) by three different chemical assays. Bioresour Technol 2008, 99:4239-4246.

44. Mouna BF, Ahmed L, Rym C-H, Jose AS, María JJ: Characterization and quantification of phenolic compounds and antioxidant properties of Salvia species growing in different habitats. Ind Crop Prod 2013, 49:904-914.

45. Belaqziz R, Harrak R, Romane A, Oufdou K, El Alaoui ElFels MA: Antimicrobial and insecticidal activities of the endemic Thymus broussonetti boiss. and Thymus maroccanus ball. Rec Nat Prod 2010, 4:230-237.

46. Soković M, Marin PD, Brkić D, van Griensven LJLD: Chemical composition and antibacterial activity of essential oils of ten aromatic plants against human pathogenic bacteria. Food 2007, 1:1

47. Bektas T, Cengiz S, Seyda B, Ahmet A, Askin A: Chemical composition, radical scavenging and antimicrobial activity of the essential oils of Thymus boveii and Thymus hyemalis. Rec Nat Prod 2011, 5:208-220.

48. Burt S: Essential oils: their antibacterial properties and potential applications in foods-a review. Int J Food Microbiol 2004, 94:223-253.

49. Giweli A, Džamić AM, Soković M, Ristić MS, Marin PD: Antimicrobial and antioxidant activities of essential oils of Satureja thymbra growing wild in Libya. Molecules 2012, 17:4836-4850.

50. Lu Y, Foo LY: Polyphenolics of Salvia -a review. Phytochemistry 2001, 59:117-140.

51. Viljoen A, van Vuuren $S$, Ernst E, Klepser M, Demirci B, Baser H, van Wyk BE: Osmitopsis asteriscoides (Asteraceae) - the antimicrobial activity and essential oil composition of a Cape-Dutch remedy. J Ethnopharmacol 2003, 88:137-143.

52. Andrews RE, Parks LW, Spence KD: Some effects of Douglas fir terpenes on certain microorganisms. Applied Env Microbiol 1980, 40:301-304.

53. Uribe $S$, Ramirez T, Pena A: Effects of a-pinene on yeast membrane functions. J Bacteriol 1985, 161:1195-1200.

54. Nikaido H: Prevention of drug access to bacterial targets. Science 1994 264:382-388.

55. Pattnaik S, Subramanyam VR, Bapaji M, Kole CR: Antibacterial and antifungal activity of aromatic constituents of essential oils. Microbiol 1997, 89:39-46.

56. Rota MC, Herrera A, Martínez RM, Sotomayor JA, Jordán MJ: Antimicrobial activity and chemical composition of Thymus vulgaris, Thymus zygis and Thymus hyemalis essential oils. Food Control 2008, 19:681-687.

\section{doi:10.1186/1476-511X-13-114}

Cite this article as: Fatma et al:: In-vitro assessment of antioxidant and antimicrobial activities of methanol extracts and essential oil of Thymus hirtus sp. algeriensis. Lipids in Health and Disease 2014 13:114.

\section{Submit your next manuscript to BioMed Central and take full advantage of:}

- Convenient online submission

- Thorough peer review

- No space constraints or color figure charges

- Immediate publication on acceptance

- Inclusion in PubMed, CAS, Scopus and Google Scholar

- Research which is freely available for redistribution 